\section{Tumor macrophage target fuels \$1.7-billion deal}

On October 26, Bristol-Myers Squibb (BMS) and Five Prime Therapeutics signed a deal worth up to $\$ 1.05$ billion over an antibody targeting CSF-1R (colony stimulating factor-1 receptor) in oncology indications. The New York-based pharma paid $\$ 350$ million up front for an exclusive license to the biotech's FPA008 monoclonal antibody and $\$ 340$ million in milestones for nononcology indications. CSF-1R has become a popular target in oncology, with as many as nine agents, including antibodies and small molecules, in clinical development. Much expectation surrounds CSF-1R inhibitors' and their potential to synergize with immune checkpoint inhibitors to overcome the immunosuppressive microenvironment in tumors. Tumor-associated macrophages (TAMs), a distinct macrophage subtype, contribute to that milieu by secreting immunosuppressive cytokines like interleukin-10. TAMs also express high levels of CSF-1R, and tumors express high levels of the ligand, CSF-1. Blocking their interaction or interrupting CSF-1R signaling with drugs could thus further unleash T cells, making immune checkpoint blockade much more effective. Proof of principle for CSF-1R inhibitors has been achieved in pigmented villonodular synovitis (PVNS), a rare tumor of the synovial lining of joints. PVNS is usually caused by a translocation causing CSF-1 overexpression. Basel-based Roche and Plexxikon (fully owned by Japanese pharmaceutical Daiichi Sankyo) have reported a greater than $80 \%$ response rate in this population for their respective agents in phase 1 trials, with minimal toxicity. But in common tumors, CSF-1 inhibition has a much more modest outcome. In May at the ASCO annual meeting, Carlos Alberto GomezRoca of the University Cancer Institute of Toulouse reported phase 1 results for Baselbased Roche's RG7155 (emactuzumab) monotherapy in solid tumors. Of 80 patients treated, there were no objective responses by standard criteria. But "about half of patients experienced stable disease as best response, which is a tricky result in phase 1 trial patients," Gomez-Roca said. A phase 1 combination trial with Roche's atezolizumab anti-programmed cell death ligand 1 (PD-L1) is underway. Similarly, whether S. San Francisco-based Five Prime and BMS will prosper from their October deal depends on FPA008's ability to make BMS's Opdivo (nivolumab) even more effective. The phase 1 combination trial began in June and will enroll 270 patients in several hard-to-treat tumors, including lung and pancreatic cancers. are calling for a shift from a voluntary system to mandatory oversight, and for labeling of all GM foods. Existing laws would enable the agencies to make these and other fundamental changes, said Doug Gurian-Sherman, a senior scientist at the Center for Food Safety in Washington, DC, who spoke at the meeting and corresponded later with Nature Biotechnology. Indeed, the FDA in November released long awaited guidance on voluntary labeling of GM food.

Opinions were divided over the fundamental idea of whether the triggers for regulatory oversight should be based on the process by which the product was made, or the risk of the product in its intended use. Michael Hansen, a senior scientist at Consumers Union in Yonkers, New York, argued for a processbased system, saying that anything made using genetic engineering should trigger regulatory oversight. "The definition of genetic engineering should be broad enough to include all new gene editing technologies and RNAi [RNA interference] technologies," he said in the meeting.

The downside to a process-based system is that it may not catch all risky products, said Kelly Drinkwater, a biosafety generalist at Boston-based iGEM foundation, who spoke at the meeting. She said, based on her experience with the student competition in synthetic biology iGEM holds, she thinks the triggers for additional oversight have to be based on the product and its use. "We find it is the only way to encompass the unimaginable diversity of synthetic biology projects," she said.

Terry Medley, global director of corporate regulatory affairs for Dupont in Wilmington, Delaware, and former administrator at the USDA's Animal and Plant Health Inspection Service, called for a more risk-based system in which regulatory requirements are commensurate with risk. He also called for expedited reviews and exemptions for familiar products. Val Giddings, a senior fellow at Information Technology \& Innovation Foundation in Washington, DC, said the coordinated framework should "restore some semblance of balance between the degree of regulatory oversight and the level of hazard presented by the products that are subject to that oversight."

Others, such as Gurian-Sherman, at the Center for Food Safety, called for more extensive testing. The agencies should assess "all types of risks, including long-term food safety risks and indirect environmental harm, which are currently inadequately regulated," he said. The center and other groups have argued in several lawsuits brought against the USDA that the agency's environmental assessments have been inadequate (Nat. Biotechnol. 27, 970, 2009). The Center in November vowed to sue the FDA for inadequate assessment of GM salmon.

To stay up to date with technology, Richard Engler, a senior chemist at the environmental law firm Bergeson \& Campbell in Washington, DC, suggested that technology stewards be embedded in each of the relevant federal agencies. Their role would be to monitor emerging technologies and hold regular briefings with industry and academic innovators.

Small and mid-sized biotech companies were absent from public comments at the meeting, despite the White House calling attention in the memo to the unique challenges they face. "I'm going to guess that some small companies might be afraid to speak out at a public meeting on regulating their product," because it might bring unwanted attention, Kuzma says. "My guess is the agencies are talking individually with the small companies to get a sense of what products are coming down the landscape."

Like a lot of public meetings, the format provided only for taking turns to speak, rather than a true conversation or back-andforth. The deadline for written comments was November 13. Two more public meetings will be held in the next year, according to a White House blog post that accompanied the memo.

Emily Waltz Nashville, Tennessee

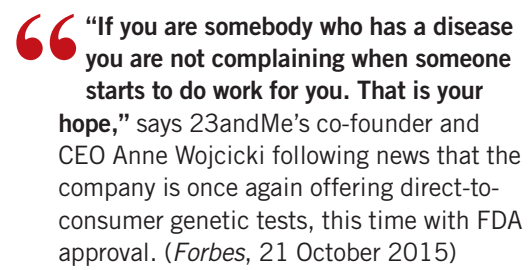

"The FDA cares about every word on the page here," says Brad Kittredge, 23andMe's vice president of product. The FDA has given 23andMe the go-ahead to sell tests that indicate carrier status for 36 genetic diseases. (Forbes, 21 October 2015) 